\title{
Article \\ Step Coverage and Dry Etching Process Improvement of Amorphous Carbon Hard Mask
}

\author{
Zheng Jiang ${ }^{1}$, Hao Zhu ${ }^{1,2}$, Qingqing Sun ${ }^{1,2, *}$ and Davidwei Zhang ${ }^{1,2}$ \\ 1 State Key Laboratory of ASIC and System, School of Microelectronics, Fudan University, Shanghai 200433, \\ China; 18112020025@fudan.edu.cn (Z.J.); hao_zhu@fudan.edu.cn (H.Z.); dwzhang@fudan.ac.cn (D.Z.) \\ 2 National Integrated Circuit Innovation Center, Shanghai 201203, China \\ * Correspondence: qqsun@fudan.edu.cn; Tel.: +86-21-65647395
}

Citation: Jiang, Z.; Zhu, H.; Sun, Q.; Zhang, D. Step Coverage and Dry Etching Process Improvement of Amorphous Carbon Hard Mask. Electronics 2021, 10, 2512. https:// doi.org/10.3390/electronics10202512

Academic Editor: Dongseok Suh

Received: 6 September 2021

Accepted: 12 October 2021

Published: 15 October 2021

Publisher's Note: MDPI stays neutral with regard to jurisdictional claims in published maps and institutional affiliations.

Copyright: (c) 2021 by the authors. Licensee MDPI, Basel, Switzerland. This article is an open access article distributed under the terms and conditions of the Creative Commons Attribution (CC BY) license (https:// creativecommons.org/licenses/by/ $4.0 /)$.

\begin{abstract}
Amorphous carbon hard mask (ACHM) films have been widely applied as protective components and hard etching masks in lithography and dry etching processes. The capability of lithography is directly dependent on the step coverage (SC) of the ACHM. Poor SC may impact the protection of device patterns during the etching process and lead to overlay marks occurring in lithography. In this work, the ACHM film processing process is engineered and optimized towards better $\mathrm{SC}$ through the comparative study of the $\mathrm{C}_{2} \mathrm{H}_{2}$ and $\mathrm{C}_{3} \mathrm{H}_{6}$ precursors at different temperatures. Furthermore, a process parameter design of experiment (DOE), with $\mathrm{C}_{2} \mathrm{H}_{2}$ as a precursor to optimize the dry etching rate, is proposed. The results of the experiment show that the dry etching performance is enhanced by higher power, temperature and $\mathrm{C}_{2} \mathrm{H}_{2}$ flow, and a smaller gap, lower pressure and lower carrier gas flow. A selective etching ratio of $\mathrm{SiO}_{2}$ and $\mathrm{SiN}$, with an improved process window, is obtained. ACHM film elimination process is also validated by characterizing the surface roughness. The demonstrated results can be instructive in terms of the optimization of etching process in future semiconductor manufacturing.
\end{abstract}

Keywords: amorphous carbon hard mask; step coverage; dry etching; lithography; surface roughness

\section{Introduction}

For the scaling of the critical sizes of semiconductor devices down to sub-100 nm, advanced hard mask films, with superior performance to those of conventional polymer resistors, are required [1-3]. With the emergence of new technologies and structures, such as double patterning and high aspect ratio patterns, lithographic and etching processes are becoming more difficult and less popular due to their use of thin photoresistors [4]. Hence, the bending or wiggling of the patterns can easily occur. For the passivation layer in memory or logic devices, as shown in Figure 1, one of the key challenges relates to obtaining a hard mask (HM) with better step coverage (SC) and a higher selective etching ratio in lithographic and dry etching processes, which is important due to special requirements of stacked layers and easier elimination to ensure good surface roughness. The amorphous carbon hard mask (ACHM) has been applied to the fabrication of semiconductors, replacing the conventional $\mathrm{SiO}_{2}$ or $\mathrm{Si}_{3} \mathrm{~N}_{4}$ hard mask due to its excellent physical properties and chemical stability. ACHM can be deposited using a variety of deposition methods, among which the plasma-enhanced chemical vapor deposition (PECVD) method has been widely used because of its high productivity, low cost, and tenability in terms of its film properties [5-7]. However, experimental studies focusing on the simultaneous optimization of the film step coverage and dry etching characteristics, using different parameters, have rarely been conducted and reported.

In this work, $\mathrm{C}_{2} \mathrm{H}_{2}$ and $\mathrm{C}_{3} \mathrm{H}_{6}$ reactant sources are employed to compare the sidewall and bottom SC at $200{ }^{\circ} \mathrm{C}$ and $400{ }^{\circ} \mathrm{C}$, respectively. The etching rate performance with the $\mathrm{C}_{2} \mathrm{H}_{2}$ carbon source is further studied for different process parameters. An optimum deposition parameter of ACHMs with boosted selective etching ratios of $\mathrm{SiO}_{2}$ and 
$\mathrm{SiN}$ is experimentally studied. The ACHM elimination process can be also validated by characterizing the surface roughness after $\mathrm{O}_{2}$ the cleaning of plasma.

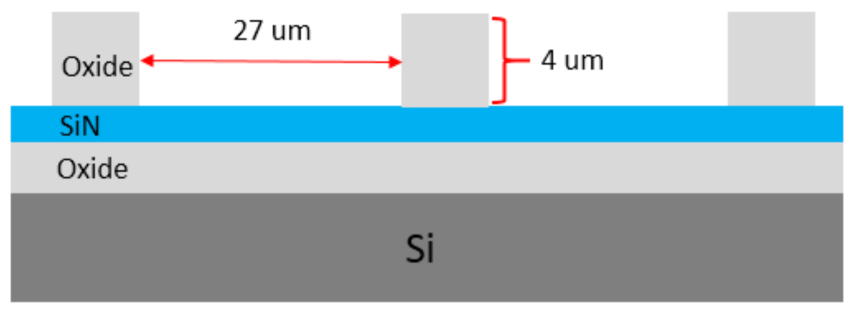

Figure 1. The target structure for film stacking of the passivation layer in a memory device.

\section{Materials and Methods}

ACHM films with different thickness of $650 \mathrm{~nm}$ and $1000 \mathrm{~nm}$ were deposited on p-type $\mathrm{Si}$ substrates via the PECVD method, employing $\mathrm{C}_{2} \mathrm{H}_{2}$ and $\mathrm{C}_{3} \mathrm{H}_{6}$ as carbon sources. In detail, after the cleaning of wafers with diluted $\mathrm{HF}$ and $\mathrm{SC} 1$ solution, the wafers were loaded in the PECVD chamber for ACHM deposition with $550 \mathrm{~W}$ RF power. The flow rates of $\mathrm{C}_{2} \mathrm{H}_{2}$ and $\mathrm{C}_{3} \mathrm{H}_{6}$ were both $650 \mathrm{sccm}$, with a reactor pressure of 4 torr. Different deposition temperatures of $200{ }^{\circ} \mathrm{C}$ and $400{ }^{\circ} \mathrm{C}$ were used, and the SC ratio and film structure were characterized by cross sectional scanning electron microscopy (SEM).

One design of experiment (DOE) method was used and eight parameters of a $\mathrm{C}_{2} \mathrm{H}_{2}-$ based ACHM process were investigated, as illustrated in Table 1. The experiment was conducted with high and low radio frequencies (HRF and LRF), power levels, temperatures, pressure levels, and gaps (the distances between the plasma and target wafer). $\mathrm{C}_{2} \mathrm{H}_{2}$ was the final precursor for ACHM, and Argon ( $\mathrm{Ar}$ ) and helium (He) were used as carrier gases of $\mathrm{C}_{2} \mathrm{H}_{2}$. The dry etching rates were measured by a Spectroscopic Ellipsometer, which was obtained from KLA-Tencor Aleris 8500. The chemical structure and C-H bonding were measured by Raman spectroscopy. The deposited film was etched using $\mathrm{O}_{2}$ plasma as well as a mixture of $\mathrm{CF}_{4}$ and $\mathrm{CHF}_{3}$. The film thickness was measured after each deposition and etching process, and the dry etching selectivity was further calculated. The surface roughness was measured using the Vicco Dimension-X AFM system.

Table 1. DOE experimental parameters of the $\mathrm{C}_{2} \mathrm{H}_{2}$-based ACHM process studied in this work.

\begin{tabular}{|c|c|c|c|c|c|c|c|c|}
\hline Exp. & $\begin{array}{l}\text { Temperature } \\
\left({ }^{\circ} \mathrm{C}\right)\end{array}$ & HRF(W) & $\operatorname{LRF}(\mathrm{W})$ & $\begin{array}{c}\mathrm{C}_{2} \mathrm{H}_{2} \\
(\mathrm{sccm})\end{array}$ & $\begin{array}{c}\mathrm{He} \\
(\mathrm{sccm})\end{array}$ & $\begin{array}{c}\mathrm{Ar} \\
(\mathrm{sccm})\end{array}$ & $\begin{array}{l}\text { Press. } \\
\text { (Torr) }\end{array}$ & $\begin{array}{c}\text { Gap } \\
(\mathrm{mm})\end{array}$ \\
\hline 1 & A-200 & B & $\mathrm{C}$ & $\mathrm{D}$ & $\mathrm{E}$ & $\mathrm{F}$ & G & $\mathrm{H}$ \\
\hline 2 & A-100 & B & $\mathrm{C}$ & $\mathrm{D}$ & $\mathrm{E}$ & $\mathrm{F}$ & G & $\mathrm{H}$ \\
\hline 3 & A & B & $\mathrm{C}$ & $\mathrm{D}$ & $\mathrm{E}$ & $\mathrm{F}$ & G & $\mathrm{H}$ \\
\hline 4 & A & B-150 & $\mathrm{C}$ & $\mathrm{D}$ & $\mathrm{E}$ & $\mathrm{F}$ & G & $\mathrm{H}$ \\
\hline 5 & A & B-150 & $C-100$ & $\mathrm{D}$ & $\mathrm{E}$ & $\mathrm{F}$ & G & $\mathrm{H}$ \\
\hline 6 & A & B-150 & $C+30$ & $\mathrm{D}$ & $\mathrm{E}$ & $\mathrm{F}$ & G & $\mathrm{H}$ \\
\hline 7 & A & $B+50$ & $\mathrm{C}$ & $\mathrm{D}$ & $\mathrm{E}$ & $\mathrm{F}$ & G & $\mathrm{H}$ \\
\hline 8 & A & $B+50$ & $C+30$ & $\mathrm{D}$ & $\mathrm{E}$ & $\mathrm{F}$ & G & $\mathrm{H}$ \\
\hline 9 & A & $B+50$ & C-100 & $\mathrm{D}$ & $\mathrm{E}$ & $\mathrm{F}$ & G & $\mathrm{H}$ \\
\hline 10 & A & B & C-100 & $\mathrm{D}$ & $\mathrm{E}$ & $\mathrm{F}$ & G & $\mathrm{H}$ \\
\hline 11 & A & B & $C+30$ & $\mathrm{D}$ & $\mathrm{E}$ & $\mathrm{F}$ & G & $\mathrm{H}$ \\
\hline 12 & A & B & $\mathrm{C}$ & D-150 & $\mathrm{E}$ & $\mathrm{F}$ & G & $\mathrm{H}$ \\
\hline 13 & A & B & $\mathrm{C}$ & $\mathrm{D}+200$ & $\mathrm{E}$ & $\mathrm{F}$ & G & $\mathrm{H}$ \\
\hline 14 & A & B & $\mathrm{C}$ & $\mathrm{D}$ & E-1000 & $\mathrm{F}$ & G & $\mathrm{H}$ \\
\hline 15 & A & B & $\mathrm{C}$ & $\mathrm{D}$ & E-500 & $\mathrm{F}$ & G & $\mathrm{H}$ \\
\hline 16 & A & B & $\mathrm{C}$ & $\mathrm{D}$ & $E+1000$ & $\mathrm{~F}$ & G & $\mathrm{H}$ \\
\hline 17 & $\mathrm{~A}$ & B & $\mathrm{C}$ & $\mathrm{D}$ & $\mathrm{E}$ & F-2000 & G & $\mathrm{H}$ \\
\hline 18 & A & B & $\mathrm{C}$ & $\mathrm{D}$ & $\mathrm{E}$ & $F+1000$ & G & $\mathrm{H}$ \\
\hline 19 & A & B & $\mathrm{C}$ & $\mathrm{D}$ & $\mathrm{E}$ & $F+2000$ & G & $\mathrm{H}$ \\
\hline 20 & $\mathrm{~A}$ & B & $\mathrm{C}$ & $\mathrm{D}$ & $\mathrm{E}$ & $\mathrm{F}$ & G-1 & $\mathrm{H}$ \\
\hline
\end{tabular}


Table 1. Cont.

\begin{tabular}{lllllllll}
\hline Exp. & $\begin{array}{c}\text { Temperature } \\
\left({ }^{\circ} \mathrm{C}\right)\end{array}$ & HRF(W) & LRF(W) & $\begin{array}{c}\mathrm{C}_{2} \mathrm{H}_{2} \\
(\mathbf{s c c m})\end{array}$ & $\begin{array}{c}\mathrm{He} \\
(\mathbf{s c c m})\end{array}$ & $\begin{array}{c}\text { Ar } \\
(\mathbf{s c c m})\end{array}$ & $\begin{array}{c}\text { Press. } \\
(\text { Torr) }\end{array}$ & $\begin{array}{c}\mathrm{Gap} \\
(\mathbf{m m})\end{array}$ \\
\hline 21 & $\mathrm{~A}$ & $\mathrm{~B}$ & $\mathrm{C}$ & $\mathrm{D}$ & $\mathrm{E}$ & $\mathrm{F}$ & $\mathrm{G}+1$ & $\mathrm{H}$ \\
22 & $\mathrm{~A}$ & $\mathrm{~B}$ & $\mathrm{C}$ & $\mathrm{D}$ & $\mathrm{E}$ & $\mathrm{F}$ & $\mathrm{G}+4$ & $\mathrm{H}$ \\
23 & $\mathrm{~A}$ & $\mathrm{~B}$ & $\mathrm{C}$ & $\mathrm{D}$ & $\mathrm{E}$ & $\mathrm{F}$ & $\mathrm{G}$ & $\mathrm{H}+1$ \\
24 & $\mathrm{~A}$ & $\mathrm{~B}$ & $\mathrm{C}$ & $\mathrm{D}$ & $\mathrm{E}$ & $\mathrm{F}$ & $\mathrm{G}$ & $\mathrm{H}+2$ \\
25 & $\mathrm{~A}$ & $\mathrm{~B}$ & $\mathrm{C}$ & $\mathrm{D}$ & $\mathrm{E}$ & $\mathrm{F}$ & $\mathrm{G}$ & $\mathrm{H}+4$ \\
\hline
\end{tabular}

\section{Results}

Figure 2 shows the SC ratio with different carbon sources and different levels of ACHM film thickness, measured by SEM, as a function of the deposition temperature. The sidewall and bottom SC exhibited similar trends for different carbon sources and thicknesses. For the $650 \mathrm{~nm}$ ACHM at a temperature of $200{ }^{\circ} \mathrm{C}$, when using $\mathrm{C}_{2} \mathrm{H}_{2}$ to replace $\mathrm{C}_{3} \mathrm{H}_{6}$, the sidewall SC ratio was improved, increasing from $53.2 \%$ to $67.3 \%$, and the bottom SC ratio was also increased from $85.1 \%$ to $87.8 \%$. Similarly, for the $1000 \mathrm{~nm}$ ACHM at a temperature of $400{ }^{\circ} \mathrm{C}$, the sidewall and bottom SC ratios were improved, increasing from $45.7 \%$ to $67.1 \%$, and from $93.0 \%$ to $107.9 \%$, respectively. Therefore, the thinner film had better sidewall SC; this was because the deposition rate became slower in the sidewall compared to the top and bottom for this pattern.

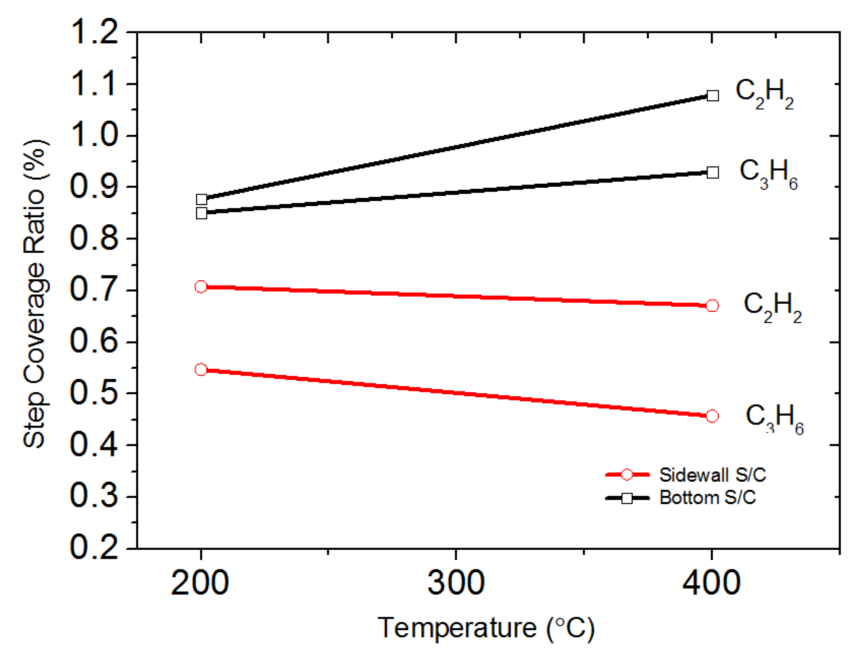

Figure 2. Results for the sidewall and bottom $\mathrm{SC}$ obtained using $\mathrm{C}_{3} \mathrm{H}_{6}$ and $\mathrm{C}_{2} \mathrm{H}_{2}$ carbon sources, respectively.

Figure 3 shows the cross-sectional SEM images of the SC performance obtained using $\mathrm{C}_{3} \mathrm{H}_{6}$ and $\mathrm{C}_{2} \mathrm{H}_{2}$ as carbon sources at $200{ }^{\circ} \mathrm{C}$ and $400{ }^{\circ} \mathrm{C}$, with $650 \mathrm{~nm}$ and $1000 \mathrm{~nm}$ thickness, respectively. The SC performance observed using $\mathrm{C}_{2} \mathrm{H}_{2}$ for different temperatures and thicknesses showed a smoother profile than that observed when using $\mathrm{C}_{3} \mathrm{H}_{6}$ at the top, sidewall, corner and bottom locations. Furthermore, the film was discontinuous at the sidewall and corner at temperatures below $400{ }^{\circ} \mathrm{C}$ when using $\mathrm{C}_{3} \mathrm{H}_{6}$. However, for the $\mathrm{C}_{2} \mathrm{H}_{2}$ carbon source, the film showed not only continuous morphology but also better SC at the sidewall and corner.

The results obtained in this experiment theoretically confirm that the ratio of $\mathrm{C} / \mathrm{H}$ in hydrocarbon species is strongly correlated with the sticking efficiency of the hydrogenated film reaction behaviors, and the sticking efficiency improves with the increasing of the $\mathrm{C} / \mathrm{H}$ ratio [8,9]. Our experimental results further verify the theory that the $\mathrm{C} / \mathrm{H}$ ratios obtained using $\mathrm{C}_{2} \mathrm{H}_{2}$ are higher than those obtained using $\mathrm{C}_{3} \mathrm{H}_{6}$. In addition, the $\mathrm{ACHM}$ obtained using the $\mathrm{C}_{2} \mathrm{H}_{2}$ precursor in this study also enabled superior $\mathrm{SC}$ performance in terms of the alignment and the overlay marks in the lithography process. 

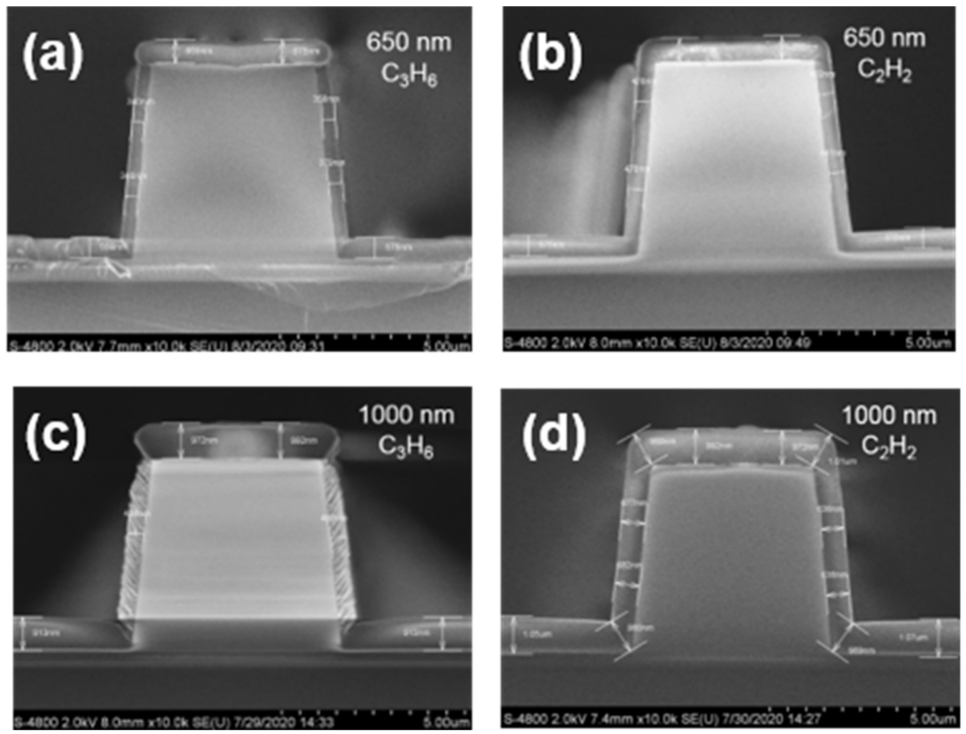

Figure 3. The SEM images showing the cross section of SC performance of different ACHM thicknesses with $\mathrm{C}_{3} \mathrm{H}_{6}$ and $\mathrm{C}_{2} \mathrm{H}_{2}$ as carbon sources: $650 \mathrm{~nm}$ ACHM at $200{ }^{\circ} \mathrm{C}$ obtained using (a) $\mathrm{C}_{3} \mathrm{H}_{6}$ and (b) $\mathrm{C}_{2} \mathrm{H}_{2} ; 1000 \mathrm{~nm}$ ACHM at $400{ }^{\circ} \mathrm{C}$ obtained using (c) $\mathrm{C}_{3} \mathrm{H}_{6}$ and (d) $\mathrm{C}_{2} \mathrm{H}_{2}$.

The transparent performance of the ACHM when using $\mathrm{C}_{2} \mathrm{H}_{2}$ was also better than that obtained with the $\mathrm{C}_{3} \mathrm{H}_{6}$ precursor. Figure 4 shows the Raman shift of the D and G-peaks with the increasing of the deposition temperature. With the increasing of the temperature from $200{ }^{\circ} \mathrm{C}$ to $400{ }^{\circ} \mathrm{C}$, the position of the $\mathrm{D}$ and G-peaks, when using $\mathrm{C}_{2} \mathrm{H}_{2}$, shifted from 1365.01 to $1347.81 \mathrm{~cm}^{-1}$, and from 1576.81 to $1586.29 \mathrm{~cm}^{-1}$, respectively, while for ACHM, with the use of $\mathrm{C}_{3} \mathrm{H}_{6}$, the $\mathrm{D}$ and G-peaks shifted from 1372.27 to $1353.25 \mathrm{~cm}^{-1}$, and from 1579.81 to $1591.56 \mathrm{~cm}^{-1}$, respectively. Such a positive shift in the G-peak position was due to the increase in the size and number of $\mathrm{sp}^{2}$ bonding carbon clusters. The negative shift in the D-peak position suggests better transparency of the ACHM film [10].

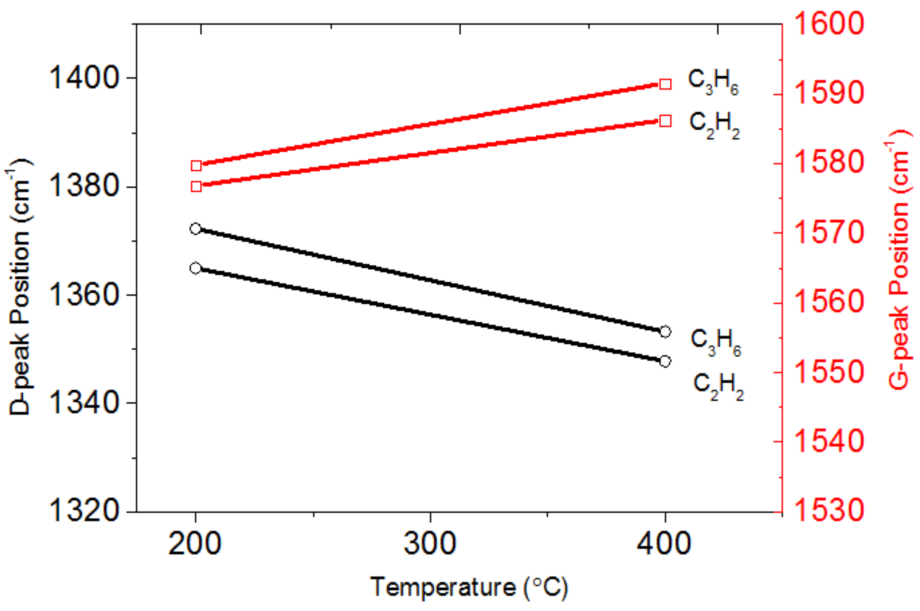

Figure 4. Raman shift for D-peak and G-peak positiion with carbon source of $\mathrm{C}_{3} \mathrm{H}_{6}$ and $\mathrm{C}_{2} \mathrm{H}_{2}$.

From the above results, it can be concluded that the thinner ACHM film, when using $\mathrm{C}_{2} \mathrm{H}_{2}$, had better SC and transparency performance than that obtained when using $\mathrm{C}_{3} \mathrm{H}_{6}$. Such performance is critical for hard masks in lithography applications due to the direct impact on the yield data and process cost. Furthermore, the etching selectivity of ACHM as a hard etching mask is another important parameter in the etching process. An optimized design of experiment (DOE) was carried out to seek the key parameters of $\mathrm{C}_{2} \mathrm{H}_{2}$ as a precursor to improve the etching performance, as shown in Table 1. 
As shown in Figure 5a, LRF could obtain a lower etching rate (ER) and higher HRF, and LRF power could also obtain a lower ER, which enabled improvements in the durability of etching. However, further increasing the HRF and LRF power did not provide an obvious improvement in the ER. In the plasma processing process, the injection of ion flux through the plasma sheath could be increased by the increased number of ions. LRF had a larger bias voltage, and as the power increased, the ions had sufficient energy to bake $\mathrm{H}$ and also to overcome to damage inflicted on the large graphitic $\mathrm{sp}^{2}$ structures, which resulted in dense film [11,12]. Higher power also enhanced the neutral and ion bombardment energy to the surface, which increased the building of sp3 structures. Therefore, these two parameters both brought greater benefits in terms of deceasing the etching rate during the etching process [13].
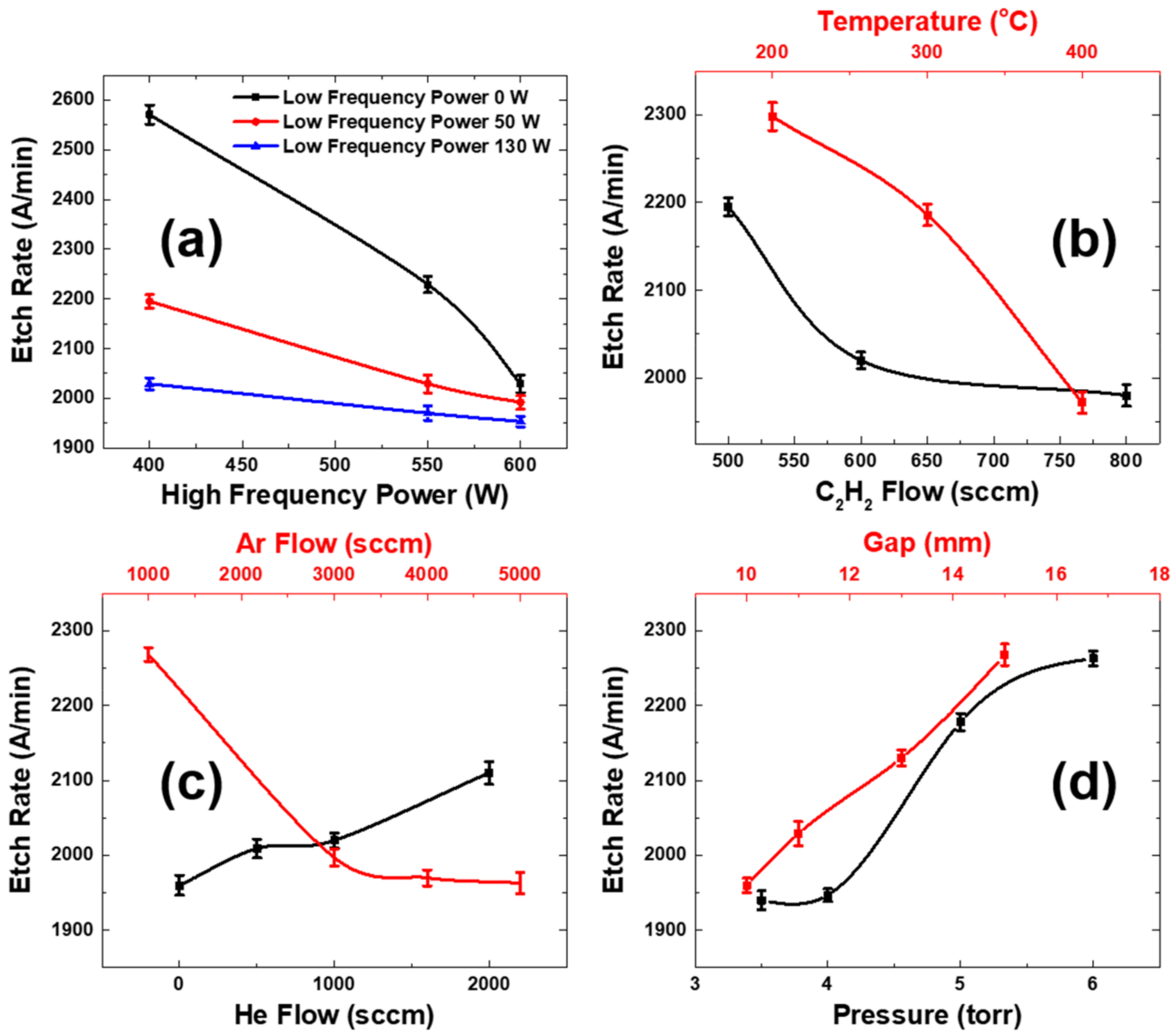

Figure 5. Dependence of ACHM ER on (a) HRF and LRF power, (b) temperature and $\mathrm{C}_{2} \mathrm{H}_{2}$ flow, (c) Ar and He flow, and (d) gap and pressure.

Figure $5 b$ shows the dependence of ER on the temperature and the $\mathrm{C}_{2} \mathrm{H}_{2}$ flow rate. Lower ER was enabled by using higher temperatures and larger $\mathrm{C}_{2} \mathrm{H}_{2}$ gas flow rates. The ER improvement ratios, obtained by increasing the temperature and $\mathrm{C}_{2} \mathrm{H}_{2}$ flow, were about $14.2 \%$ and $9.8 \%$, respectively. Under higher temperatures, it was easier for the hydrogen to bake out from the surface, which was more vulnerable to carbon ionic and radical chemisorption. As a result, the ACHM film became denser. The dependence of ER on the He and Ar flow rates was further studied. As shown in Figure 5c, the dependence on Ar and He carrier gases showed different behaviors, and lower ER was observed with higher Ar gas flow rates and also with lower He gas flow rates. This was the case because, in general, the total gas flow increases the Ar flow rate more significantly when the pressure and gap of the chamber remain constant. This will increase gas density, leading to more particle collisions. Therefore, the mean free path of the charged particles is reduced and the film density is improved. However, for He flow, charged He atoms can be easily pumped from the exhaust port due to the lower molecular weight, which will slightly lower the heat 
in the chamber, and thus, will dissipate the effect of film deposition and density [14,15]. Ar gas flow is a more sensitive parameter than He gas flow for ER optimization.

Figure $5 \mathrm{~d}$ shows the relationship between ER and the pressure and gap, and a similar trend is observed for both parameters with a lowered ER under decreasing pressures and gaps. The ER was improved from $2263 \AA / \mathrm{min}$ to $1947 \AA / \mathrm{min}$ with the decreasing of the pressure from 6 torr to 4 torr. However, the ER was improved from $2268 \AA / \mathrm{min}$ to $1960 \AA / \mathrm{min}$ by decreasing the gap from $15 \mathrm{~mm}$ to $10 \mathrm{~mm}$. The ER improvement ratios were $13.9 \%$ and $13.6 \%$ for the decreasing of the pressure and gap, respectively. The two parameters were both shown to be key parameters in terms of improving the etching durability of ACHM. According to the supplantation model, the pressure and the gap are utilized to determine the mean free path, and a lower pressure and gap would increase the ionic bombardment of the plasma, and thus, would improve the chemisorption of energetic carbonic ions [16,17]. As for pressure, such a phenomenon can be explained by the variation of the surface hydrogen coverage such that the adsorption and decomposition of the source molecules can react only at the region that does not have hydrogen atom coverage on the substrate [18]. Absorbed hydrogen atoms are produced by the decomposition of source molecules, and the density of the dangling bond sites where the source molecules can be adsorbed becomes smaller as the pressure becomes higher. Therefore, the ion bombardment energy will be increased in the low pressure to improve the count of $\mathrm{sp}^{2}$, which can be beneficial in terms of film hardness [19]. Therefore, ACHM film is improved with higher density and hardness.

Based on the above DOE results, optimized deposition process parameters could be obtained with improved dry etching selective ratios, which were 10.3 and 7.2 for $\mathrm{SiO}_{2}$ and $\mathrm{SiN}$ at $60 \mathrm{~W}$ bias power and 0.125 torr pressure in the etching system (Figure 6). Figure 6 $\mathrm{a}$ and $\mathrm{b}$ show the AFM images of the surface roughness before and after the obtaining of clean solutions for $\mathrm{ACHM}$, with $\mathrm{C}_{2} \mathrm{H}_{2}$ as a carbon source, at $400{ }^{\circ} \mathrm{C}$. The roughness RMS values of ACHM before and after cleaning were $1.17 \mathrm{~nm}$ and $1.66 \mathrm{~nm}$, respectively, which indicates that the ACHM was effectively eliminated and that the surface roughness was adequate for memory device applications due to the effective suppression of the scattering of incident lasers during the lithography process.
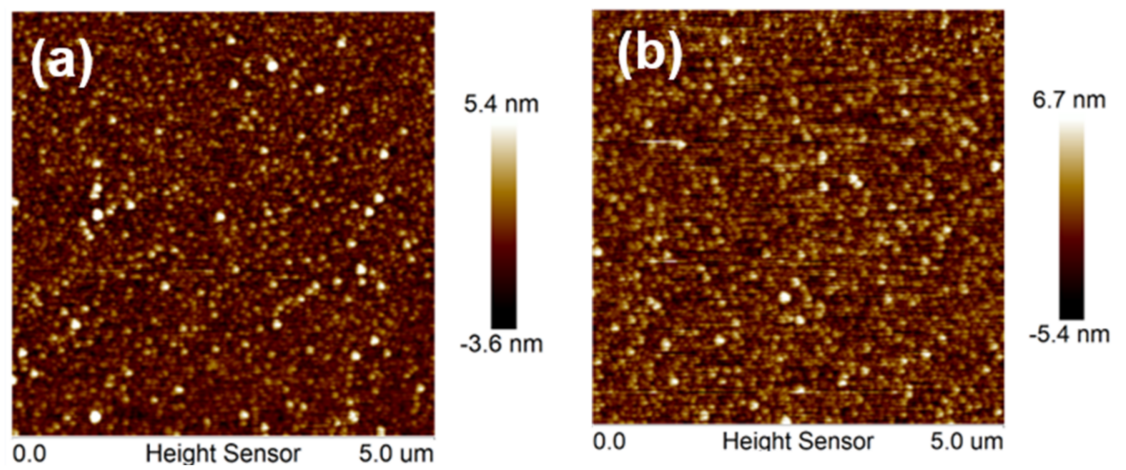

Figure 6. Dry etching rate map of the film using (a) $\mathrm{C}_{3} \mathrm{H}_{6}$ and (b) $\mathrm{C}_{2} \mathrm{H}_{2}$ at $400{ }^{\circ} \mathrm{C}$.

\section{Conclusions}

From the demonstrated experimental results, it can be seen that the SC of ACHM film properties were optimized as a result of the different temperatures and precursors used in the PECVD deposition process. With the use of higher $\mathrm{C} / \mathrm{H}$ ratios for the thinner $\mathrm{C}_{2} \mathrm{H}_{2}-$ based ACHM film, an improvement in SC was achieved as compared to the $\mathrm{C}_{3} \mathrm{H}_{6}$-based ACHM. The optimization of the etching rate performance by means of DOE, with the goal of attaining high-reliability film quality, was further studied. Based on the DOE results and analysis, it can be concluded that the dry etching rate was enhanced by higher power, temperature and $\mathrm{C}_{2} \mathrm{H}_{2}$ flow, and lower pressure, smaller gaps and reduced carrier gas flow. The optimized process condition was achieved with dry etching selective ratios of 10.3 and 7.2 for $\mathrm{SiO}_{2}$ and $\mathrm{SiN}$, respectively. The effective ACHM film elimination that was achieved 
in this study also provides a good basis for lithography processes involving with smooth surfaces. Our results show great potential for applications involving dry etching using hard masks in the fabrication of advanced semiconductor devices.

Author Contributions: Investigation, Z.J.; Resources, Q.S.; Supervision, D.Z.; Writing-review and editing, H.Z. All authors have read and agreed to the published version of the manuscript.

Funding: This work was supported by the National Key Research and Development Program of China (2017ZX02315005) and the Support Plans for the Youth Top-Notch Talents of China.

Data Availability Statement: The data presented in this study are available on request from the corresponding author.

Conflicts of Interest: The authors declare no conflict of interest.

\section{References}

1. Park, S.H.; Kim, Y.; Kim, W.; Seo, J.Y.; Park, B.-G. Vertical-Channel STacked ARray (VCSTAR) for 3D NAND flash memory. Solid-State Electron. 2012, 78, 34-38. [CrossRef]

2. Pauliac-Vaujour, S.; Brianceau, P.; Comboroure, C.; Faynot, O. Improvement of high resolution lithography by using amorphous carbon hard mask. Microelectron. Eng. 2008, 85, 800-880. [CrossRef]

3. Lee, G.; Hwang, S.; Yu, J.; Kim, H. Architecture and Process Integration Overview of 3D NAND Flash Technologies. Appl. Sci. 2021, 11, 6703.

4. Ho, C.Y.; Lin, X.J.; Chien, H.R.; Lien, C. High aspect ratio contact hole etching using relatively transparent amorphous carbon hard mask deposition from propylene. Thin Solid Films 2010, 518, 6076-6079. [CrossRef]

5. Negishi, N.; Takesue, H.; Sumiya, M.; Yoshida, T.; Momonoi, Y.; Izawa, M. Deposition control for reduction of $193 \mathrm{~nm}$ photoresist degradation in dielectric etching. J. Vac. Sci. Technol. B 2005, 23, 217-223. [CrossRef]

6. Kim, J.K.; Cho, S.I.; Kim, N.G.; Jhon, M.S.; Min, K.S.; Kim, C.K.; Yeom, G.Y. Study on the etching characteristics of amorphous carbon layer in oxygen plasma with carbonyl sulfide. J. Vac. Sci. Technol. A 2013, 31, 021301. [CrossRef]

7. Suhdi, S.; Wang, S.-C. The Production of Carbon Nanofiber on Rubber Fruit Shell-Derived Activated Carbon by Chemical Activation and Hydrothermal Process with Low Temperature. Nanomaterials 2021, 11, 2038. [CrossRef] [PubMed]

8. Sciammarella, F.M.; Najafabadi, B.S. Processing Parameter DOE for 316L Using Directed Energy Deposition. J. Manuf. Mater. Process. 2018, 2, 61. [CrossRef]

9. Pohlen, M.; Pirker, L.; Dreu, R. The Potential of Macroporous Silica-Nanocrystalline Cellulose Combination for Formulating Dry Emulsion Systems with Improved Flow Properties: A DoE Study. Pharmaceutics 2021, 13, 1177. [CrossRef] [PubMed]

10. Lee, S.; Jung, D.; Yang, J.; Boo, J.-H.; Kim, H.; Lee, J.; Chae, H. Characterization of oxygen and nitrogen rapid thermal annealing processes for ultra-low-k SiCOH films. J. Mater. Res. 2008, 23, 856-861. [CrossRef]

11. Von Keudell, A. Formation of polymer-like hydrocarbon films from radical beams of methyl and atomic hydrogen. Thin Solid Films 2002, 402, 1-37. [CrossRef]

12. Sugiyama, N.; Hirashita, N.; Mizuno, T.; Moriyama, Y.; Takagi, S. Analysis of growth rate during Si epitaxy by hydrogen coverage model. Mater. Sci. Semicond. Process. 2005, 8, 11-14. [CrossRef]

13. Lee, S.; Won, J.; Choi, J.; Jang, S.; Jee, Y.; Lee, H.; Byun, D. Preparation and analysis of amorphous carbon films deposited from (C6H12)/Ar/He chemistry for application as the dry etch hard mask in the semiconductor manufacturing process. Thin Solid Films 2011, 519, 6737-6740. [CrossRef]

14. Borghesani, A.F. Accurate Electron Drift Mobility Measurements in Moderately Dense Helium Gas at Several Temperatures. Atoms 2021, 9, 52. [CrossRef]

15. Rizo-Gorrita, M.; Luna-Oliva, I.; Serrera-Figallo, M.-A.; Torres-Lagares, D. Superficial Characteristics of Titanium after Treatment of Chorreated Surface, Passive Acid, and Decontamination with Argon Plasma. J. Funct. Biomater. 2018, 9, 71. [CrossRef] [PubMed]

16. Kim, K.P.; Song, W.S.; Park, M.K.; Hong, S.J. Surface Analysis of Amorphous Carbon Thin Film for Etch Hard Mask. J. Nanosci. Nanotechnol. 2021, 21, 2032-2038. [CrossRef] [PubMed]

17. Reinke, P.; Jacob, W.; Möller, W. Influence of the ion energy on the growth and structure of thin hydrocarbon films. J. Appl. Phys. 1993, 74, 1354-1361. [CrossRef]

18. Suenitsu, M.; Nakazawa, H.; Morita, T.; Miyamoto, N. Observation of Hydrogen-Coverage- and Temperature-Dependent Adsorption Kinetics of Disilane on Si(100) during Si Gas-Source Molecular Beam Epitaxy. Jpn. J. Appl. Phys. 1997, $36,625$.

19. Cao, Y.Z.; Liang, Y.C.; Dong, S.; Sun, T.; Wang, B. Effects of the Substrate on the Determination of SEBS Thin Film Mechanical Properties by Nanoindentation. Key Eng. Mater. 2006, 315-316, 766-769. [CrossRef] 